\title{
ANALISA FAKTOR-FAKTOR YANG MEMPENGARUHI KECURANGAN LAPORAN KEUANGAN : MODEL FRAUD DIAMOND
}

\author{
Ramdany $^{1}$, Risha Musfita ${ }^{2}$, Hidayat Darwis ${ }^{3}$ \\ ${ }^{1}$ STIE Muhammadiyah Jakarta, ramdany2012@gmail.com \\ ${ }^{2}$ STIE Muhammadiyah Jakarta, rishamusfita98@gmail.com \\ ${ }^{3}$ STIE Muhammadiyah Jakarta, hidayat_mm@yahoo.co.id
}

\begin{abstract}
ABSTRAK
Penelitian ini bertujuan untuk menganalisa faktor-faktor yang mempengaruhi kecurangan laporan keuangan dengan model fraud diamond. Variabel independen adalah pressure, opportunity, rationalization, capability dan variabel dependen adalah kecurangan laporan keuangan. Populasi dalam penelitian ini adalah perusahaan yang terdaftar di Bursa Efek Indonesia (BEI) tahun 2014-2018 dengan purposive sampel sebanyak 100 perusahaan. Teknik analisis data menggunakan regresi linier berganda. Hasil analisis menunjukkan bahwa pressure dengan proksi personal financial need berpengaruh negatif terhadap kecurangan laporan keuangan. Opportunity dengan proksi nature of industry berpengaruh positif terhadap kecurangan laporan keuangan. Namun pressure dengan proksi external pressure, opportunity dengan proksi ineffective monitoring, rationalization dan capability tidak berpengaruh terhadap kecurangan laporan keuangan.
\end{abstract}

Kata Kunci : Pressure, Opportunity, Rationalization, Capability, Kecurangan Laporan Keuangan

\begin{abstract}
This study aims to analyze the factors that influence fraudulent financial statements with a fraud diamond model. The independent variable is pressure, opportunity, rationalization, capability and the dependent variable is fraudulent financial statement. The population in this study is companies listed on the Indonesia Stock Exchange (IDX) in 2014-2018 with a purposive sample of 100 companies. Data analysis techniques using multiple linear regression. The result of the analysis shows that the pressure with a personal financial need proxy has a negative effect on the fraudulent financial statements. Opportunity with the nature of industry proxy positive effect on the fraudulent financial statement. Whereas pressure with external pressure proxy, opportunity with ineffective monitoring, rationalization, and capability proxies have no effect on fraudulent financial statements.
\end{abstract}

Keywords: Pressure, Opportunity, Rationalization, Capability, Fraudulent Financial Statement.

\section{PENDAHULUAN}

Kecurangan merupakan tindakan yang dilakukan secara sengaja oleh individu atau badan usaha yang mengakibatkan kerugian terhadap individu, entitas atau pihak lainnya (ACFE, 2016). Fraud merupakan bahaya laten yang mengancam dunia (Nugraheni \& Triatmoko, 2017). Hasil survei ACFE (2018) kasus fraud terhadap laporan keuangan di dunia terus meningkat setiap tahunnya. Pada tahun 2014 kasus kecurangan laporan 
keuangan sebesar 9\% dari 1.483 kasus fraud, kemudian tahun 2016 meningkat menjadi 9,6\% dari 2.410 kasus, dan pada tahun 2018 meningkat menjadi $10 \%$ dari 2.690 kasus.

Grafik 1. Jumlah Kasus Kecurangan di Dunia

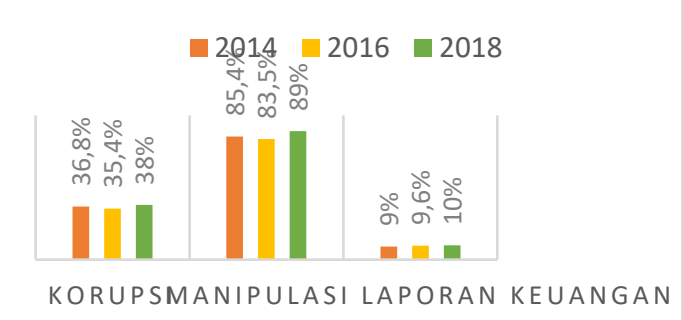

Sumber: Association of Certified Fraud Examiner (ACFE), 2018 (data diolah)

Kasus kecurangan laporan keuangan terjadi di dunia seperti kasus Thosiba Corporation (2015) terbukti menggelembungkan laba selama lima tahun berturut-turut sebesar US\$ 1,22 miliar (liputan6.com, 2015). Tahun 2017 perusahaan British Telecom di Italia melakukan fraud terhadap laporan keuangan dengan transaksi fiktif, invoice palsu dan rekayasa perpanjangan kontrak (wartaekonomi.co.id, 2017). Pada tahun 2019 General Electric Company di New York terjerat kasus manipulasi laporan keuangan dengan penggelembungan di unit asuransi hingga US\$ 18,5 milyar (CNBC Indonesia, 2019).

Kasus kecurangan laporan keuangan juga terjadi di beberapa perusahaan di Indonesia, seperti kasus PT Cakra Mineral Tbk (2016) menggelembungkan nilai aset dan melebihkan nilai modal yang disetor oleh pemegang saham sehingga merugikan investor yang lainnya (Beritalima.com, 2016). Pada tahun 2019 PT Hanson Internasional Tbk melakukan pelanggaran peraturan perundang-undangan di bidang pasar modal karena tidak mengungkapkan perjanjian pengikatan jual beli kavling siap bangun senilai $\mathrm{Rp} 732$ milyar dalam laporan keuangannya (msn.com, 2019).
Kecurangan laporan keuangan terjadi karena adanya tekanan serta dorongan dan motivasi dari pelaku untuk merekaya laporan keuangan agar terlihat optimal kinerja perusahaan dengan tujuan menarik perhatian investor dan meningkatkan harga saham perusahaan (Rahmatikal, 2019). Kerugian yang timbul dari kecurangan laporan keuangan menyebabkan kerugian cukup signifikan dan dapat mempengaruhi kelangsungan usaha perusahaan dalam jangka panjang. Kondisi terburuk yang dapat dialami oleh perusahaan karena tindakan tersebut adalah kebangkrutan (Aviantara, 2019). Oleh karena itu diperlukan pendeteksian dan tindakan pencegahan agar fraud atas laporan keuangan tidak terjadi.

SAS No. 99 (AICPA, 2002) menjelaskan bahwa pressure dibagi menjadi empat bagian yaitu external pressure, personal financial need, financial stability dan financial target. Sedangkan opportunity dibagi menjadi tiga bagian yaitu organizational structure, ineffective monitoring dan nature of industry. Faktor rationalization dan capitability bagian yang tersendiri dalam fraud diamond.

Penelitian Indarto \& Ghozali (2016), Syahputra \& Erlina (2019), Fajri (2018), Fathia et al (2019), Diansari \& Wijaya (2018) dan Premananda et al (2019) menunjukkan bahwa pressure dengan proksi external pressure berpengaruh positip terhadap kecurangan laporan keuangan. Namun hasil penelitian Sunardi \& Amin (2018), Wailan'An et al., (2019), Putra (2019), Yendrawati et al., (2019), Yulianti et al., (2019), Siregar et al., (2019) serta Aviantara (2019) menunjukkan bahwa pressure dengan proksi external pressure tidak berpengaruh positip terhadap kecurangan laporan keuangan.

Selanjutnya penelitian Kusumaningrum \& Murtanto (2016), Nugraheni \& Triatmoko (2017), 
Premananda et al., (2019), Fajri (2018), Hariyanto (2019) dan Sari \& Lestari (2020) menunjukkan bahwa pressure dengan proksi personal financial need berpengaruh positif terhadap kecurangan laporan keuangan. Namun penelitian Tiffani \& Marfuah (2015), Prasmaulida (2016), Inayanti \& Sukirman (2016), Diansari \& Wijaya (2018) dan Wailan'An et al., (2019) menunjukkan bahwa pressure dengan proksi personal financial need tidak berpengaruh positip terhadap kecurangan laporan keuangan.

Penelitian Inayanti \& Sukirman (2016), dan Syahputra \& Erlina (2019) menunjukkan bahwa opportunity dengan proksi nature of industry berpengaruh positip terhadap kecurangan laporan keuangan. Namun Manurung \& Hardika (2015) dan Husmawati et al (2017) menunjukkan bahwa opportunity dengan proksi nature of industry tidak berpengaruh positip terhadap kecurangan laporan keuangan. Penelitian Syahputra \& Erlina (2019), Siregar et al., (2019), Agusputri \& Sofie (2019), Lestari \& Henny (2019) dan Fathia et al., (2019) menunjukkan bahwa opportunity dengan proksi ineffective monitoring berpengaruh positip terhadap kecurangan laporan keuangan. Namun penelitian Manurung \& Hardika (2015), Indarto \& Ghozali (2016), Husmawati et al., (2017), Yulianti et al., (2019), Premananda et al., (2019) dan Wailan'An et al., (2019) menunjukkan bahwa opportunity dengan proksi ineffective monitoring tidak berpengaruh positip terhadap kecurangan laporan keuangan.

Penelitian Premananda et al (2019), Pramana et al (2019) dan Syahria et al (2019) menunjukkan bahwa rationalization berpengaruh positip terhadap kecurangan laporan keuangan. Namun penelitian Putra (2019), Wailan'An et al., (2019), Yulianti et al., (2019) dan Rahmatika et al., (2019) menunjukkan bahwa rationalization tidak berpengaruh positip terhadap kecurangan laporan keuangan.

Penelitian Manurung \& Hardika (2015), Premananda et al (2019), Utami \& Pusparini (2019), Triyanto (2019) dan Syahputra \& Erlina (2019) menunjukkan bahwa capability berpengaruh terhadap kecurangan laporan keuangan. Berbeda dengan hasil penelitian Rengganis et al (2019), Rahmatika (2019), Yendrawati et al (2019) dan Antawirya et al(2019) menunjukkan bahwa capability tidak berpengaruh positip terhadap kecurangan laporan keuangan.

Berdasarkan fenomena diatas dan adanya gap antara teori dengan realitas lapangan, penelitian ini bertujuan untuk mengali lebih mendalam faktor-faktor yang mempengaruhi kecurangan (fraud) melalui pendekatan teori fraud diamond. Penelitian ini akan memperkaya penelitian sebelumnya dengan menggunakan data penelitian yang terbaru dan diharapkan dapat menghasilkan temuan baru dalam penyelesaian permasalahan yang menyangkut kecurangan dalam laporan keuangan.

\section{TINJAUAN PUSTAKA}

\section{Agency Theory}

Teori agensi Jensen \& Meckling (1979) menjelaskan hubungan antara agent (manajemen) dan principal (pemegang saham). Menurut teori keagenan terdapat perbedaan kepentingan dalam hubungan antara agent dan principal yang dapat memicu konflik kepentingan (conflict of interest).

\section{Fraud}

Fraud merupakan upaya untuk mendapatkan keuntungan dengan cara yang tidak jujur (unfair) seperti pernyataan atau pengungkapan yang salah, fakta palsu, menipu, pemikiran yang salah dijustifikasi benar (Romney \& Steinbart, 
2014). Menurut ACFE (2016) fraud merupakan tindakan yang dilakukan secara sengaja oleh individu atau badan sehingga mengakibatkan kerugian.

\section{Kecurangan Laporan Keuangan}

Kecurangan laporan keuangan adalah tindakan penipuan yang mengakibatkan representasi menyesatkan, salah saji material atau melaporkan sumber daya keuangan entitas bisnis secara tidak tepat (Margret \& Peck, 2014). Tindakan kecurangan laporan keuangan merupakan kegiatan manipulasi laporan keuangan yang disengaja dengan cara merubah catatan beserta buktinya yang berdampak menyesatkan keputusan pengguna laporan keuangan (Crain, 2015).

\section{Fraud Diamond}

Wolfe \& Hermanson (2004) mengemukakan fraud diamond theory yang merupakan pengembangan dari fraud triagle theory. Dalam fraud diamond theory ada unsur baru yang mempengaruhi terjadinya fraud yaitu adanya kemampuan (capability). Faktor-faktor pendorong kecurangan dalam laporan keuangan menurut fraud diamond theory adalah, tekanan(Pressure),Kesempatan(Opportun ity), Rasionalisasi(Rationalization),

Kemampuan (Capability)

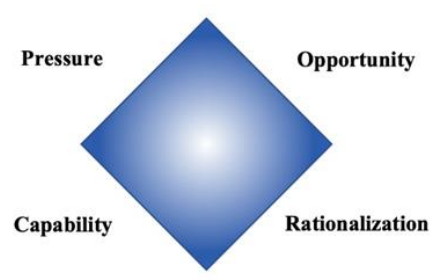

Sumber: Wolfe and Hermanson, 2004

Gambar 1. Fraud Diamond

\section{Pengembangan Hipotesis}

Tekanan kepada manajemen dari pihak ketiga (external pressure) agar menjalankan operasional perusahaan sesuai dengan keinginan atau harapannya merupakan salah faktor yang menyebabkan terjadinya fraud ((Indarto \& Ghozali, 2016). Penelitian yang dilakukan oleh Indarto \& Ghozali (2016), Syahputra \& Erlina (2019), Fajri (2018), Fathia (2019), Diansari \& Wijaya (2018) dan Premananda (2019) menyatakan bahwa external pressure yang dengan indikator leverage rasio (total kewajiban dibanding dengan total asset) secara signifikan mempengaruhi kecurangan laporan keuangan. Berdasarkan uraian diatas dapat dirumuskan hipotesis sebagai berikut:

\section{$\mathrm{H}_{\mathrm{a}} \mathrm{l}$ : Pressure dengan indicator external pressure berpengaruh positif terhadap kecurangan laporan keuangan}

Personal financial need adalah kebutuhan financial eksekutif perusahaan. Menurut Indarto \& Ghozali (2016) kinerja keuangan perusahaan mempengaruhi kebutuhan financial eksekutif. Semakin tinggi kinerja perusahaan semakin tinggi tingkat kebutuhan financial eksekutif. Umumnya eksekutif perusahaan memiliki sebagai saham saham diperusahaan. Hal ini merupakan cara yang digunakan eksekutif untuk mempertahankan kebutuhan financialnya. Eksekutif perusahaan yang memiliki sebagian saham perusahaan dapat mempengaruhi kebijakan manajemen dalam mengungkapkan kinerja keuangannya. Berdasarkan uraian diatas dapat dirumuskan hipotesis sebagai berikut:

\section{$\mathrm{H}_{\mathrm{a}} 2$ : Pressure dengan indikator personal financial need berpengaruh positif terhadap kecurangan laporan keuangan}

Nature of industry adalah sipat lingkungan industry. Perusahaan menghadapi risiko salah satunya adalah lingkungan bisnis. Risiko bisnis perusahaan menurut Noble (2019) dapat mendorong terjadinya kecurangan terhadap laporan keuangan. Tujuan manipulasi laporan keuangan adalah 
mempertahankan kinerja perusahaan agar kelihatan optimal dan kepentingan pribadi.Berdasarkan uraian diatas, maka dirumuskan hipotesis sebagai berikut :

\section{$\mathrm{H}_{\mathrm{a}} 3$ : Opportunity dengan proksi nature}

of industry berpengaruh positif terhadap kecurangan laporan keuangan

Ineffective monitoring adalah suatu kondisi di mana belum terdapat devisi atau unit pemantauan yang efektif untuk mengendalikan dan mengawasi semua kegiatan operasional di perusahaan sehingga berpotensi timbulnya fraud (Prasmaulida, 2016). Beberapa perusahaan belum memiliki (minim) komisaris independen. Minimnya jumlah komisaris independent berpotensi terjadinya manipulasi terhadap laporan keuangan (Skousen et al. 2009).

Penelitian yang dilakukan Lestari \& Henny (2019) dan Fathia et al. (2019) menyatakan bahwa ineffective monitoring dengan indikator rasio proporsi dewan komisaris independen secara positip signifikan mempengaruhi kecurangan laporan keuangan. Semakin kecil rasio proporsi dewan komisaris independen maka akan semakin tidak efektif pengawasan dalam memantau kinerja perusahaan, sehingga semakin tinggi kecenderungan melakukan kecurangan dalam laporan keuangan. Berdasarkan uraian diatas, maka dirumuskan hipotesis sebagai berikut :

\section{$\mathrm{H}_{\mathrm{a}} 4$ : Opportunity dengan proksi ineffective monitoring berpengaruh positif terhadap kecurangan laporan keuangan}

Rasionalisasi adalah pembenaran pemikiran terhadap tindakan yang salah (Rahmatika et al, 2019). SAS No. 99 menyatakan bahwa penunjukkan auditor independent untuk memeriksa laporan keuangan perusahaan adalah tindakan rasionalisasi manajemen. Manajemen lebih menyukai auditor yang dapat menyesuaikan dengan keinginan manajemen. Beberapa auditor yang dianggap tidak sejalan dengan keinginan manajemen umumnya tidak bertahan lama. Perusahaan yang berpotensi melakukan manipulasi pada laporan keuangan cenderung lebih sering melakukan pergantian auditor. Berdasarkan uraian diatas, maka dirumuskan hipotesis sebagai berikut :

$\mathrm{H}_{\mathrm{a}} 5$ : Rationalization dengan proksi change of auditor berpengaruh positif terhadap kecurangan laporan keuangan

Perubahan direksi terlalu sering mengindikasikan adanya fraud (Wolfe \& Hermanson, 2004). Penelitian yang dilakukan oleh Manurung \& Hardika (2015), Premananda et al (2019), Utami \& Pusparini (2019), Triyanto (2019) dan Syahputra \& Erlina (2019), menyatakan bahwa capability diproksikan dengan change of direktors positip signifikan mempengaruhi kecurangan laporan keuangan. Berdasarkan uraian diatas, maka dirumuskan hipotesis sebagai berikut :

Ha6 : Capability dengan proksi change of direktors berpengaruh positif terhadap kecurangan laporan keuangan.

Kerangka Pemikiran

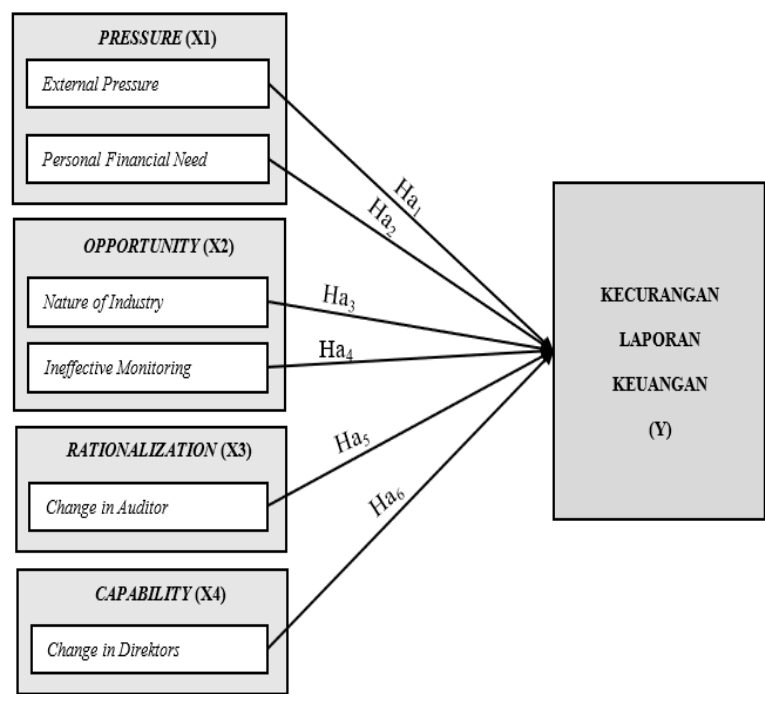

Gambar 2. Kerangka Pemikiran 


\section{Populasi dan Sampel Penelitian}

Penelitian ini merupakan penelitian kausal. Populasi yang digunakan dalam penelitian ini adalah seluruh perusahaan yang terdaftar di Bursa Efek Indonesia (BEI) tahun 2014-2018 sebanyak 619 perusahaan. Penentuan sampel menggunakan teknik slovin sebagai berikut :

$$
\begin{gathered}
n=\frac{619}{1+619(0,1)^{2}} \\
n=\frac{619}{7,19} \\
n=86,09
\end{gathered}
$$

(n-sampel disesuaikan oleh peneliti menjadi 100 perusahaan)

Metode pengambilan sampel menggunakan purposive sampling. Kriteria pemilihan sampel dalam penelitian ini adalah:

1. Perusahaan yang menjadi sampel merupakan perusahaan acak yang terdaftar di Bursa Efek Indonesia selama periode 2014-2018

2. Perusahaan memiliki data terkait penelitian ini seperti akun-akun tertentu untuk digunakan dalam perhitungan yang berhubungan dengan proksi variabel dependen dan variabel independen.

3. Perusahaan yang menggunakan mata uang rupiah $(\mathrm{Rp})$

Berdasarkan teknik slovin dan kriteria pemilihan sampel didapat sebanyak 100 perusahaan sebagai sampling pengamatan tahun 2014-2018.

Persamaan regresi linear berganda dalam penelitian ini sebagai berikut:

$$
\begin{aligned}
\text { Fraud }=\alpha_{0} & +\beta_{1} \text { LEV }+\beta_{2} \text { OSHIP } \\
& +\beta_{3} \text { RECEIVABLE } \\
& +\beta_{4} \text { BDOUT }+\beta_{5} \Delta C P A \\
& +\beta_{6} \text { DCHANGE }+e
\end{aligned}
$$

\begin{tabular}{|c|c|c|c|c|}
\hline \multirow[b]{2}{*}{ Variabel } & \multicolumn{4}{|c|}{$\mathbf{N}=\mathbf{5 0 0}$} \\
\hline & Minimum & Maximum & Mean & $\begin{array}{l}\text { Standar } \\
\text { Deviasi }\end{array}$ \\
\hline Fraud & 0 & 1 & 0,31600 & 0,46538 \\
\hline LEV & 0,03939 & 1,46066 & 0,43599 & 0,18400 \\
\hline OSHIP & 0 & 1 & 0,63000 & 0,48329 \\
\hline $\begin{array}{l}\text { RECEIVA } \\
\text { BLE }\end{array}$ & $-1,32855$ & 1,85056 & 0,00225 & 0,15541 \\
\hline BDOUT & 0,16667 & 1 & 0,40840 & 0,10915 \\
\hline$\triangle \mathrm{CPA}$ & 0 & 1 & 0,38000 & 0,48587 \\
\hline $\begin{array}{l}\text { DCHANG } \\
\text { E }\end{array}$ & 0 & 1 & 0,09619 & 0,29515 \\
\hline
\end{tabular}

$\begin{array}{ll}\text { Dimana: } & \\ \text { Fraud } & \text { : Kecurangan laporan keuangan } \\ \alpha & \text { : Konstanta } \\ \beta & \text { : Koefisien Regresi } \\ \text { LEV } & \text { : Rasio tingkat kewajiban per } \\ \text { total aset } & \text { : Rasio kepemilikan saham oleh } \\ \text { OSHIP } & \\ \text { orang dalam } & \\ \text { RECEIVABLE : Rasio perubahan piutang usaha } \\ \text { BDOUT: Rasio proporsi dewan komisaris } \\ \text { independen } \\ \begin{array}{ll}\Delta \text { CPA } & \text { : Pergantian Auditor } \\ \text { DCHANGE } & : \text { Pergantian Direksi } \\ \text { e } & : \text { Standar Error }\end{array}\end{array}$

HASIL DAN PEMBAHASAN

Analisis Statistik Deskriptif

Tabel 3

Deskripsi Variabel Penelitian

Sumber: Data diolah, 2020

Variabel kecurangan laporan keuangan dihitung dengan BENEISH MSCORE dengan menggunakan variabel dummy yaitu nilai 0 untuk perusahaan yang tidak terindikasi fraud dan nilai 1 untuk perusahaan yang terindikasi fraud, sehingga nilai terendah (minimum) 0 dan nilai tertinggi (maximum) 1. Nilai rata-rata (mean) sebesar 0,31600 dan standar deviasi sebesar 0,46538 .

Variabel pressure dengan proksi external pressure yang dihitung dengan $\boldsymbol{L E} \boldsymbol{V}$ (rasio tingkat kewajiban per total aset) memiliki nilai terendah (minimum) 
sebesar 0,03939 dan nilai tertinggi (maxsimum) sebesar 1,46066.

Variabel pressure dengan proksi personal financial need yang dihitung dengan OSHIP (rasio total kepemilikan orang dalam) dengan menggunakan variabel dummy yaitu nilai 0 untuk perusahaan yang tidak terindikasi fraud dan nilai 1 untuk perusahaan yang terindikasi fraud, sehingga nilai terendah (minimum) 0 dan nilai tertinggi (maximum) 1. Nilai rata-rata (mean) sebesar 0,63000

Variabel opportunity dengan proksi nature of industry yang dihitung dengan RECEIVABLE (rasio perubahan piutang penjualan) memiliki nilai terendah (minimum) sebesar $-1,32855$ dan nilai tertinggi (maxsimum) sebesar 1,85056 . Nilai rata-rata (mean) sebesar 0,00225 dan standar deviasi sebesar 0,15541 . Nilai ratarata 0,00225 menunjukkan tingkat piutang penjualan seluruh perusahaan pada sampel penelitian ini sebesar $0,225 \%$.

Variabel opportunity dengan proksi ineffective monitoring yang dihitung dengan BDOUT (rasio proporsi dewan komisaris independen) memiliki nilai terendah (minimum) sebesar -0,16667 dan nilai tertinggi (maxsimum) sebesar 1 . Nilai rata-rata (mean) sebesar 0,40840 dan standar deviasi sebesar 0,10915. Nilai ratarata 0,40840 menunjukkan rasio anggota dewan komisaris independen sebesar $40,840 \%$.

Variabel rationalization yang dihitung dengan $\triangle$ CPA (pergantian auditor) dengan menggunakan variabel dummy yaitu nilai 0 untuk perusahaan yang tidak terindikasi fraud dan nilai 1 untuk perusahaan yang terindikasi fraud, sehingga nilai terendah (minimum) 0 dan nilai tertinggi (maximum) 1 . Nilai rata-rata (mean) sebesar 0,38000 dan standar deviasi sebesar 0,48587 . Nilai rata-rata 0,38000 menunjukkan bahwa perusahaan yang melakukan pergantian auditor hanya $38 \%$ dari total sampel.

Variabel capability yang dihitung dengan DCHANGE (pergantian direksi) dengan menggunakan variabel dummy yaitu nilai 0 untuk perusahaan yang tidak terindikasi fraud dan nilai 1 untuk perusahaan yang terindikasi fraud, sehingga nilai terendah (minimum) 0 dan nilai tertinggi (maximum) 1. Nilai rata-rata (mean) sebesar 0,09619 dan standar deviasi sebesar 0,29515. Nilai rata-rata 0,09619 menunjukkan bahwa perusahaan yang melakukan pergantian direksi hanya 9,619\% dari total sampel.

Tabel 4

Hasil Regresi Common Effect Weight

\begin{tabular}{cllll}
\multicolumn{5}{c}{ Model } \\
\hline Variable & Coeffic & Std.Er & t-Stat & Pro \\
& ient & ror & & \\
\hline C & 0.3187 & 0.0875 & 3.640 & 0.00 \\
& 68 & 71 & 108 & 03 \\
LEV & 0.0875 & 0.1058 & 0.827 & 0.40 \\
& 47 & 10 & 395 & 84 \\
OSHIP & - & & - & \\
& 0.1503 & 0.0394 & 3.809 & 0.00 \\
& 20 & 56 & 795 & 02 \\
RECEIV & 0.4415 & 0.1009 & 4.372 & 0.00 \\
ABLE & 78 & 94 & 319 & 00 \\
BDOUT & - & & & \\
& 0.0554 & 0.1791 & 0.309 & 0.75 \\
& 29 & 02 & 481 & 71 \\
$\Delta$ CPA & - & & & \\
& 0.0056 & 0.0302 & 0.187 & 0.85 \\
& 71 & 51 & 470 & 14 \\
DCHAN & - & 0.0638 & & 0.81 \\
GE & 0.0148 & 47 & 0.232 & 63 \\
& 37 & & 390 & \\
\hline \hline
\end{tabular}

Sumber: Data diolah, 2020

Berdasarkan hasil analisis dan pembahasan yang telah dilakukan dapat disimpulkan bahwa variabel pressure dengan proksi external pressure yang dihitung menggunakan leverage tidak berpengaruh terhadap kecurangan laporan keuangan. Hasil penelitian ini tidak mendukung hipotesis 1 yang menyatakan bahwa pressure dengan proksi external 
pressure berpengaruh positif terhadap kecurangan laporan keuangan. Kemudian variabel pressure dengan proksi personal financial need yang dihitung menggunakan oship berpengaruh negatif signifikan terhadap kecurangan laporan keuangan. Hasil penelitian ini tidak mendukung hipotesis 2 yang menyatakan bahwa pressure dengan proksi personal financial need berpengaruh positif terhadap kecurangan laporan keuangan.

Variabel oppotunity dengan proksi nature of industry yang dihitung menggunakan receivable berpengaruh positif signifikan terhadap kecurangan laporan keuangan. Hasil penelitian ini mendukung hipotesis 3 yang menyatakan bahwa oppotunity dengan proksi nature of industry berpengaruh positif terhadap kecurangan laporan keuangan. Selanjutnya variabel opportunity dengan proksi ineffective monitoring yang dihitung menggunakan bdout tidak berpengaruh terhadap kecurangan laporan keuangan. Hasil penelitian ini tidak mendukung hipotesis 4 yang menyatakan bahwa ineffective monitoring berpengaruh positif terhadap kecurangan laporan keuangan.

Variabel rationalization dengan proksi change of auditor tidak berpengaruh terhadap kecurangan laporan keuangan. Hasil penelitian ini tidak mendukung hipotesis 5 yang menyatakan bahwa rationalization berpengaruh positif terhadap kecurangan laporan keuangan.Variabel capability dengan proksi change of directors tidak berpengaruh terhadap kecurangan laporan keuangan. Hasil penelitian ini tidak mendukung hipotesis 6 yang menyatakan bahwa capability dengan proksi change of directors berpengaruh positif terhadap kecurangan laporan keuangan.

\section{SARAN}

Adanya perbedaan antara teori dan hasil penelitian dalam variabel pressure yang diproksi eksternal pressure dan personal finance need mengindikasikan adanya perbaikan dalam operasional manajemen. Kemampuan perusahaan dalam mengatasi tekanan dari internal dan eksternal tetap dipertahankan serta ditingkatkan dengan pola tata kelola organisasi yang baik. system pengendalian internal yang ada Perlu ditingkatkan sehingga memberikan jaminan bahwa laporan keuangan bebas salah saji material yang disebabkan faktor opportunity.

Capability yang dimiliki internal manajemen diarahkan pada hal yang positip dengan menutup rapat celah yang dapat menimbulkan fraud khususnya manipulasi laporan keuangan. Standar operasional prosedur dalam pelaporan keuangan perlu ditingkatkan sehingga laporan keuangan yang dihasilkan oleh manajemen dapat digunakan sebagai landasan dalam pengambilan keputusan oleh pihak yang berkepentingan.

Terakhir disarankan untuk penelitian selanjutnya agar menambah sampel penelitian dan tingkat error 5\% untuk mendapatkan model pengukuran kecurangan laporan keuangan yang lebih akurat. Berharap penelitian ini dapat memberikan manfaat kepada pihak berkepentingan

\section{REFERENSI}

ACFE. (2016). Global Fraud Study. Report to the Nations, 1-92.

ACFE. (2018a). Global Study on Occupational Fraud and Abuse: AsiaPacific Edition. Report to the Nations, $10,80$.

Agustinus, M. (2019). Manipulasi Laporan Keuangan Dirut PT Hanson Berujung Denda $R p \quad 5$ Miliar. Www.Msn.Com. https://www.msn.com/idid/ekonomi/ekonomi/manipulasi- 
laporan-keuangan-dirut-pt-hanson-

AICPA. (2002). Consideration of Fraud in a Financial Statement Audit. AICPA.

Hariyanto, A. (2019). Analisis Pengaruh Financial Stability, Personal Financial Need, External Pressure dan Ineffective Monitoring Terhadap Financial Statement Fraud.

Husmawati, P., Septriani, Y., Rosita, I., \& Handayani, D. (2017). Fraud Pentagon Analysis in Assessing the Likelihood of Fraudulent Financial Statement (Study on Manufacturing Firms Listed in Bursa Efek Indonesia Period 2013-2016). International Conference of Applied Science on Engineering, Business, Linguistics and Information Technology (ICoASCNITech), 45-51.

Kusumaningrum, A. W., \& Murtanto. (2016). Analisis Pengaruh Fraud Diamond Dalam Mendeteksi Kecurangan Laporan Keuangan. Jurnal Akuntansi Dan Bisnis, 2(September), 412-422.

Lestari, M. I., \& Henny, D. (2019). Pengaruh Fraud Pentagon Terhadap Fraudulent Financial Statements Pada Perusahaan Perbankan Yang Terdaftar Di Bursa Efek Indonesia Tahun 2015- 2017. Jurnal Akuntansi Trisakti, $6(1), \quad 141$. https://doi.org/10.25105/jat.v6i1.527 4

Noble, M. R. (2019). Fraud Diamond Analysus in Detecting Financial Statement Fraud. The Indonesian Accounting Review, 9(2), 121-132. https://doi.org/10.14414/tiar.v9i2.163 2

Prasmaulida, S. (2016). Financial Statement Fraud Detection Using Perspective Of Fraud Triangle
Adopted By SAS No. 99. Asia Pacific Fraud Journal, 1(2), 317-335. https://doi.org/10.21532/apfj.001.16. 01.02 .24

Priantara, D. (2017). Ketika Skandal Fraud Akuntansi Menerpa British Telecom dan PwC. Www.Wartaekonomi.Co.Id. https://www.wartaekonomi.co.id/read 145257/ketika-skandal-fraudakuntansi-menerpa-british-telecomdan-pwc

Rahmatika, D. N., Kartikasari, M. D., Indriasih, D., Sari, I. A., \& Mulia, A. (2019). Detection of Fraudulent Financial Statement; Can Perspective of Fraud Diamond Theory be applied to Property, Real Estate, and Building Construction Companies in Indonesia? European Journal of Business and Management Research, 4(6), 1-9. https://doi.org/10.24018/ejbmr.2019. 4.6.139

Siregar, A. O., Prayoga, M. A., \& Sudarmaji, E. (2019). Fraud of Financial Statements in Diamond Theory's Perspective: Empirical Study of Transportation Sub Sector Companies in The Indonesia Stock Exchange. The International Journal of Business Review (The Jobs Review), 2(1), 63-73. https://doi.org/10.17509/tjr.v2i1.231

Yulianti, Pratami, S. R., Widowati, Y. S., \& Prapti, L. (2019). Influence Of Fraud Pentagon Toward Fraudulent Financial Reporting In Indonesia An Empirical Study On Financial Sector Listed In Indonesian Stock Exchange. Yulianti,. International Journal of Scientific and Technology Research, 8(8), 237-242. 